\title{
Erratum
}

\section{Erratum to "Inhibitory Effects of Litsea cubeba Oil and Its Active Components on Aspergillus flavus"}

\author{
Shiqi Xia $\mathbb{D}^{1,}{ }^{1,2}$ Hong Lin $\left(\mathbb{D},{ }^{2}\right.$ Peilin Zhu $\mathbb{D}^{2}$, Peiling Wang $\mathbb{D}^{1},{ }^{1}$ Shengliang Liao $\left(\mathbb{D},{ }^{1}\right.$ \\ Shangxing Chen $\mathbb{D},{ }^{1}$ Zongde Wang $\mathbb{D},{ }^{1}$ and Guorong Fan $\mathbb{D}^{1}$ \\ ${ }^{1}$ College of Forestry, Jiangxi Agricultural University, \\ East China Woody Fragrance and Flavor Engineering Research Center of National Forestry and Grassland Administration, \\ Camphor Engineering Research Center of NFGA, Jiangxi Province, Nanchang 330045, China \\ ${ }^{2}$ Jiangxi Academy of Forestry, Nanchang 330032, China
}

Correspondence should be addressed to Zongde Wang; zongdewang@163.com and Guorong Fan; fgr008@126.com

Received 14 January 2021; Accepted 14 January 2021; Published 31 January 2021

Copyright (c) 2021 Shiqi Xia et al. This is an open access article distributed under the Creative Commons Attribution License, which permits unrestricted use, distribution, and reproduction in any medium, provided the original work is properly cited.

In the article titled "Inhibitory Effects of Litsea cubeba Oil and Its Active Components on Aspergillus flavus" [1], the author name Guorong Fan was omitted from the correspondence information in error. The correct correspondence line is "Correspondence should be addressed to Zongde Wang; zongdewang@163.com and Guorong Fan; fgr008@ 126.com". This mistake was introduced during the production process and Hindawi apologises for causing this error in the article.

\section{References}

[1] S. Xia, H. Lin, P. Zhu et al., "Inhibitory Effects of Litsea cubeba Oil and its Active Components on Aspergillus flavus," Journal of Food Quality, vol. 2020, Article ID 8843251, 9 pages, 2020. 